\title{
Microarray analyses of peripheral whole blood cells from ulcerative colitis patients: Effects of leukocytapheresis
}

\author{
TEPPEI KOBAYASHI, KEIICHI MITSUYAMA, HIROSHI YAMASAKI, JUNYA MASUDA, \\ HIDETOSHI TAKEDATSU, KOTARO KUWAKI, SHINICHIRO YOSHIOKA, \\ KOJI NAGAYAMA and MICHIO SATA \\ Division of Gastroenterology, Department of Medicine, Kurume University School of Medicine, \\ Kurume 830-0011, Japan
}

Received October 12, 2012; Accepted December 5, 2012

DOI: $10.3892 / \mathrm{ijmm} .2013 .1270$

\begin{abstract}
Complementary DNA microarray technology allows the simultaneous analysis of the expression of hundreds to thousands of genes. We applied this technique to clarify the molecular mechanisms underlying the therapeutic effects of leukocytapheresis (LCAP) therapy in patients with ulcerative colitis (UC). A 776-gene microarray analysis was performed using whole blood cells from six normal subjects and six patients with active UC who had undergone filtration LCAP. Widespread gene upregulation was observed in patients with UC, compared with normal subjects. After LCAP, genes with proinflammatory actions, such as CD97, CD74, human leukocyte antigen-DR $\beta 1$ and -DP light chain, were downregulated, while genes responsible for antimicrobial actions, such as neutrophil gelatinase-associated lipocalin, and acute phase reactions, such as haptoglobin $\alpha 1 \mathrm{~S}$ and $\alpha 1$-acid glycoprotein, were upregulated. In conclusion, we identified several genes expressed in the whole blood cells of UC patients as well as the transcriptional events following LCAP. Following LCAP, the gene profile shifted toward a pattern indicating disease improvement. These results suggest a basis for the molecular mechanisms leading to the therapeutic effects of LCAP and also indicate new therapeutic targets, providing important prognostic information.
\end{abstract}

\section{Introduction}

Ulcerative colitis (UC), a type of inflammatory bowel disease (IBD), is a complex clinical entity in which genetic, environmental and microbial factors interact to determine

Correspondence to: Dr Keiichi Mitsuyama, Division of Gastroenterology, Department of Medicine, Kurume University School of Medicine, Asahi-machi 67, Kurume 830-0011, Japan

E-mail: ibd@med.kurume-u.ac.jp

Key words: gene expression, leukocytapheresis, microarray, ulcerative colitis the susceptibility response of immune and non-immune cellular systems mediating inflammation (1-3). Although the precise mechanisms of pathogenesis remain unclear, studies using radiolabeled leukocytes (4) or immunohistochemical techniques (5) have revealed evidence of the recruitment of circulating leukocytes to the affected bowel. During active disease, newly migrated leukocytes from the circulation may be exposed to bacteria in the gut lumen, which may further activate these cells and result in severe mucosal damage. The removal of circulating leukocytes was therefore speculated to be an attractive approach for treating UC.

Trials of therapeutic leukofiltration from the peripheral circulation, otherwise known as leukocytapheresis (LCAP), have been performed using a veno-venous extracorporeal apheresis device coupled to a leukofiltration device $(6,7)$. In several trials, LCAP appeared to attenuate inflammation in patients with UC (8-11) as well as patients with Crohn's disease (12), rheumatoid arthritis $(13,14)$ and rapidly progressive glomerulonephritis (15), without provoking severe complications. Summarizing the results of previous clinical reports, Ortolano et al (8) concluded that $76 \%$ of 115 patients with IBD who were treated using LCAP entered remission, obviating the need for ongoing corticosteroid or cytoablative support. However, the mechanisms underlying these therapeutic effects have not been fully clarified.

As a breakthrough technology in the development of modern functional research in the field of human genomebased science, complementary DNA (cDNA) microarrays have become a powerful and sensitive technique that can be broadly applied to both basic and clinical research. This method makes it practical to quantitatively and simultaneously measure the expression levels of a large number of genes and has been successfully used to observe alterations and variations in gene expression in a variety of cells and tissues. In three previous studies, gene expression in IBD tissue, either from patients with UC or Crohn's disease, was compared with that in noninflamed or inflamed control tissue using cDNA microarrays (16-18). These experiments resulted in the identification of a large number of genes that are differentially expressed in the mucosa of patients with IBD, including genes that have been previously associated with IBD as well as candidate genes that have not been previously associated with IBD (16). 
In the present study, we used cDNA microarrays to investigate, for the first time, the global gene expression profiles of whole blood cells from patients with UC who had received LCAP. Our results suggest a basis for the molecular mechanisms leading to the therapeutic effects of LCAP and indicate new therapeutic targets, providing important prognostic information.

\section{Materials and methods}

Characteristics of subjects. The characteristics of the normal subjects and patients examined in this study are shown in Table I. Six patients with active UC were enrolled (3 men, 3 women; mean age, 27.5 years; mean disease duration, 6.2 years). Patients had either left-sided colitis $(n=3)$ or pancolitis $(n=3)$ and were classified into the moderate $(n=3)$ or severe $(n=3)$ attack categories, according to the Truelove and Witts criteria (19). All patients received standard medical therapy with aminosalicylates and/or corticosteroids. Patients with any of the following features were excluded from the study: an age $<18$ or $>80$ years, a serum hemoglobin $<8 \mathrm{~g} / \mathrm{dl}$, a total leukocyte count $<4,000 / \mu 1$, or coagulation abnormalities, bleeding diathesis, pregnancy or unsuitable peripheral venous access for apheresis. The apheresis procedure was well tolerated by all the patients. No severe complications occurred during the procedure. Informed consent was obtained from all the patients prior to undergoing LCAP. Blood samples from age- and gender-matched healthy volunteers were examined as normal controls.

LCAP procedure. LCAP was performed using a Cellsorba $\mathrm{E}$ column (Asahi Kasei Medical, Tokyo, Japan) installed in the extracorporeal circulation system (Plasauto LC; Asahi Kasei Medical) (6,7). For apheresis, venous access was secured via two large peripheral veins, and the blood was anticoagulated with nafamostat mesilate (Torii Pharmaceutical, Tokyo, Japan), a protease inhibitor that inhibits the activity of coagulation factors and platelet aggregation (6,7,9-15). Heparin was not used, since its use has been associated with respiratory distress and palpitations (20). With a flow rate of 30-50 ml/min for $60 \mathrm{~min}$, a total of $\sim 3$ liters of blood was treated during each session. In principle, the LCAP procedure was carried out weekly for 5 weeks.

Preparation of RNA from blood. Samples (2.5 $\mathrm{ml}$ x2) of whole blood were drawn into PAXgene Blood RNA tubes (Qiagen, Hilden, Germany), and total RNA was extracted and purified according to the manufacturer's instructions. The quantity of RNA obtained from the extraction step was assessed using a NanoDrop ND-1000 instrument (NanoDrop Technologies, Wilmington, DE). The quality of the extracted RNA was determined using a Bioanalyser 2100 (Agilent Technologies, Palo Alto, CA, USA). A ribosomal RNA 28S/18S ratio above 1.3 was verified for all experiments.

Preparation of the cDNA microarray. We designed and prepared a low-density cDNA microarray for mRNA expression profiling in whole blood. Genes for this microarray were selected from the public database of SAGE results (http://133.11.248.12/; homepage of Department of Molecular
Preventative Medicine, School of Medicine, University of Tokyo) prepared from activated blood cells, such as T cells, dendritic cells, monocytes, and macrophages (21-24). As described previously (24), a total of 776 genes were spotted onto SuperAmine (Telechem International, Sunnyvale, CA, USA) in quadruplicate, along with positive and negative control genes. For most of the genes, each cDNA was designed to be $\sim 500$ to $600 \mathrm{bp}$ and to be within $\sim 1 \mathrm{~kb}$ from the 3'-poly(A) tail. In addition, all cDNAs for the microarray probe were cloned into the pGEM vector (Promega, Madison, WI, USA). All clones for the capture probe were sequenced and validated by comparison with the GenBank sequence. In some cases, the 776 genes were divided into 20 groups based on their functional relatedness: lymphokine/cytokine/chemokine-related, cell surface antigen/immune response-related, kinase/kinase inhibitor-related, apoptosis/stress-related, matrix-related/ membrane-bound-related, metal-related, oncogene/suppressorrelated, cell cycle/transcription factor-related, DNA/ RNA-binding protein-related, energy/metabolism-related, drug metabolism-related, protease-related, serum protein/ anti-coagulation-related, proteasome-related, autoimmune system-related, general enzyme-related, receptor-related, ribosomal protein-related, miscellaneous, and control, according to the Atlas cDNA Expression Arrays (Clontech Laboratories, Palo Alto, CA, USA).

Reference RNA. Reference RNA was established from a mixture of whole blood (drawn into PAXgene tubes) samples obtained from healthy volunteers. The extracted total RNA, which was certified to be of sufficient quality using the Agilent RNA chip, was amplified using the MessageAmp aRNA kit (Ambion, Austin, TX, USA) to generate amplified RNA (aRNA). External non-human artificial RNA (C.elegans Y49G5B fragment) was spiked into the reference aRNA to distinguish it from the sample aRNA.

Preparation of sample RNA, labeling, hybridization and scanning. Total RNA (1 mg) from subjects was transcribed and amplified into aRNA using the MessageAmp aRNA kit, according to the manufacturer's instructions. Next, an external control RNA mixture [ $\lambda$ DNA (LD)], the baculovirus glycoprotein gene (GP), and the Renilla luciferase gene (RL); 9 mg each) were added to both the sample and reference aRNAs. The sample and reference aRNAs were then labeled with Cy5-dUTP and Cy3-dUTP (Perkin-Elmer, Boston, MA), respectively, using a SuperScript II kit (Invitrogen, Carlsbad, CA, USA) together with random hexamers (Takara, Kyoto, Japan). Competitive hybridization of the Cy3-labeled reference and the Cy5-labeled sample cDNAs on the microarray was carried out using a chamber system (Agilent Technologies), according to the method described by Khodursky et al (25). Slides were scanned five times at five different power ranges using a ScanArray 5000 (Perkin-Elmer). For further statistical analysis, the data was converted from tiff image data to signals using ImaGene software (Biodiscovery, Inc., El Segundo, CA, USA). The data files for the five scans were merged to establish a single representative data set for each gene (subject pending PCT/JP03/06677). The Cy5 (subject sample)/Cy3 (reference sample) ratio for each mRNA signal was calculated using global Lowess normalization (26). 
Table I. Characteristics of the UC patients providing samples for the cDNA microarray assay.

\begin{tabular}{|c|c|c|c|c|c|c|}
\hline \multirow[b]{2}{*}{$\begin{array}{l}\text { Patient } \\
\text { no. }\end{array}$} & \multirow[b]{2}{*}{$\begin{array}{l}\text { Age (years)/ } \\
\text { gender }\end{array}$} & \multirow[b]{2}{*}{$\begin{array}{c}\text { Disease } \\
\text { duration (years) }\end{array}$} & \multirow[b]{2}{*}{$\begin{array}{c}\text { Disease } \\
\text { extent }\end{array}$} & \multirow[b]{2}{*}{$\begin{array}{l}\text { Disease } \\
\text { activity }^{\mathrm{a}}\end{array}$} & \multicolumn{2}{|c|}{ Concomitant medications (mg/day) } \\
\hline & & & & & Prednisolone & $\begin{array}{c}\text { 5-Aminosalicylic } \\
\text { acid }\end{array}$ \\
\hline 1 & $18 / \mathrm{F}$ & 0.3 & Entire colon & Severe & 40 & 2000 \\
\hline 2 & $22 / \mathrm{M}$ & 1 & Left-side colon & Severe & 10 & 1250 \\
\hline 3 & $23 / \mathrm{F}$ & 7 & Left-side colon & Moderate & 10 & 2250 \\
\hline 4 & $25 / M$ & 5 & Entire colon & Moderate & 15 & 2250 \\
\hline 5 & $31 / \mathrm{F}$ & 9 & Left-side colon & Severe & 30 & 2250 \\
\hline 6 & $46 / M$ & 15 & Entire colon & Moderate & 5 & 2250 \\
\hline
\end{tabular}

${ }^{\mathrm{a} B a s e d}$ on the criteria of Truelove and Witts.

Table II. Cell counts in the peripheral blood of the normal subjects and the patients with ulcerative colitis.

\begin{tabular}{llccc}
\hline & & & \multicolumn{2}{c}{ Ulcerative colitis $(\mathrm{n}=6)$} \\
\cline { 4 - 5 } & & Normal subjects $(\mathrm{n}=6)$ & Before LCAP & After LCAP \\
\hline Leukocytes & $(/ \mu \mathrm{l})$ & $5283 \pm 987$ & $5900 \pm 1173$ & $8550 \pm 4142$ \\
Neutrophils & $(/ \mu \mathrm{l})$ & $3093 \pm 1067$ & $3780 \pm 1708$ & $6970 \pm 4392^{\mathrm{d}}$ \\
& $(\%)$ & $57.3 \pm 12.0$ & $61.8 \pm 17.9$ & $78.2 \pm 11.2^{\mathrm{a}, \mathrm{d}}$ \\
Eosinophils & $(/ \mu \mathrm{l})$ & $123 \pm 54$ & $172 \pm 182$ & $124 \pm 112$ \\
& $(\%)$ & $2.4 \pm 1.2$ & $3.5 \pm 4.1$ & $2.1 \pm 2.0$ \\
Basophils & $(/ \mu 1)$ & $59 \pm 47$ & $36 \pm 40$ & $41 \pm 65$ \\
& $(\%)$ & $1.2 \pm 1.1$ & $0.7 \pm 0.7$ & $0.4 \pm 0.5$ \\
Lymphocytes & $(/ \mu \mathrm{l})$ & $1760 \pm 601$ & $1608 \pm 550$ & $1285 \pm 553$ \\
& $(\%)$ & $34.3 \pm 11.8$ & $28.7 \pm 11.8$ & $17.8 \pm 9.4^{\mathrm{a}, \mathrm{d}}$ \\
Monocytes & $(/ \mu 1)$ & $240 \pm 120$ & $292 \pm 193$ & $123 \pm 78$ \\
& $(\%)$ & $4.6 \pm 2.1$ & $5.2 \pm 3.4$ & $1.5 \pm 1.1^{\mathrm{a}, \mathrm{d}}$ \\
Platelets & $\left(10^{4} / \mu 1\right)$ & $19 \pm 4$ & $30 \pm 11^{\mathrm{a}}$ & $16 \pm 5^{\mathrm{e}}$ \\
Erythrocytes & $\left(10^{4} / \mu \mathrm{l}\right)$ & $479 \pm 21$ & $378 \pm 52^{\mathrm{b}}$ & $330 \pm 41^{\mathrm{c}, \mathrm{e}}$ \\
\hline
\end{tabular}

${ }^{\mathrm{a}} \mathrm{P}<0.05,{ }^{\mathrm{b}} \mathrm{P}<0.005,{ }^{\mathrm{C}} \mathrm{P}<0.0001$ vs. normal subjects; ${ }^{\mathrm{d}} \mathrm{P}<0.05,{ }^{\mathrm{e}} \mathrm{P}<0.005$ vs. UC before LCAP.

Statistical analysis. The statistical analysis was performed using a t-test or paired t-test. Results were expressed as the mean and SD. P-values of $<0.05$ were considered to indicate a statistically significant result.

\section{Results}

Peripheral white blood cell count. Table II shows the peripheral white blood cell count in the six normal subjects and the six UC patients before and after LCAP. The absolute number and proportion of leukocyte subsets were similar between the UC patients and the normal subjects. Interestingly, the proportion of neutrophils increased and the proportion of lymphocytes and monocytes decreased in UC patients after LCAP.

Overall gene expression profiles. The cDNA microarray analyses of whole blood cells from normal subjects, UC patients before LCAP, and the same UC patients after treatment repeatedly showed heterogeneous signals (Fig. 1). Two genes were uniquely upregulated by $>2$-fold and no genes were uniquely downregulated by $>2$-fold in normal subjects, whereas five genes were uniquely upregulated and two genes were uniquely downregulated in UC patients before LCAP, and 19 genes were uniquely upregulated and 18 genes were uniquely downregulated after LCAP.

Gene expression profiles: UC patients vs. normal subjects. Fig. 2A shows the gene expression profiles of whole blood cells from UC patients vs. those from normal subjects. The genes that were upregulated by $>2$-fold in the UC patients are summarized in Table III. These genes include galactoside-binding 3 (galectin 3), immunoglobulin heavy constant $\gamma 3$, human mRNA for calcium-binding protein in macrophages (MRP-14), $\gamma-\mathrm{G}$ globin (HBG2), and interleukin-1 receptor type II (IL-1R2). In 


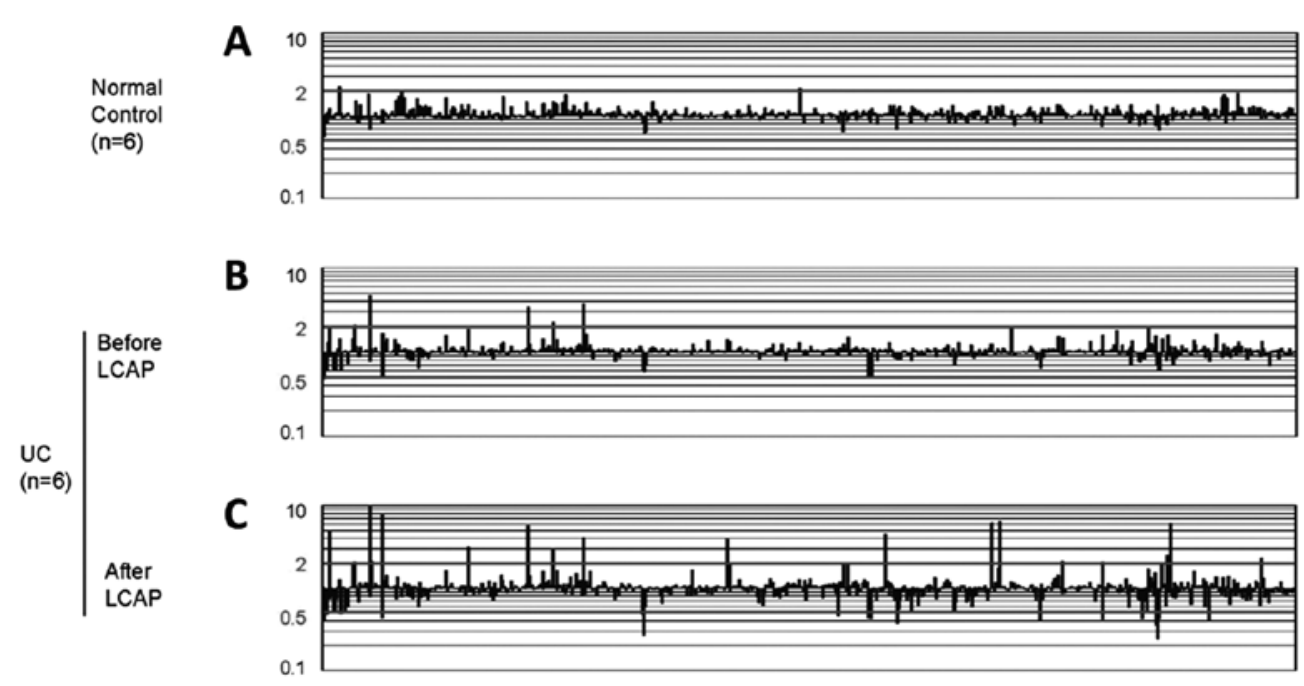

Figure 1. Global gene expression profiles of (A) normal subjects, (B) of UC patients before LCAP, and (C) of patients after LCAP. The vertical bars indicate an increase or decrease in gene expression in patients with UC, compared with gene expression in the control subjects, at a 2-fold level of the Cy5 (subject sample)/Cy3 (reference sample) ratio for each mRNA signal. 'Downregulated' designates genes that are downregulated, compared with the control profile at a 2 -fold level; 'upregulated' indicates genes that are upregulated, compared with the control profile at a 2 -fold level. 'No significant change' indicates genes that are expressed within the 2 -fold level. The horizontal bars represent the gene number.

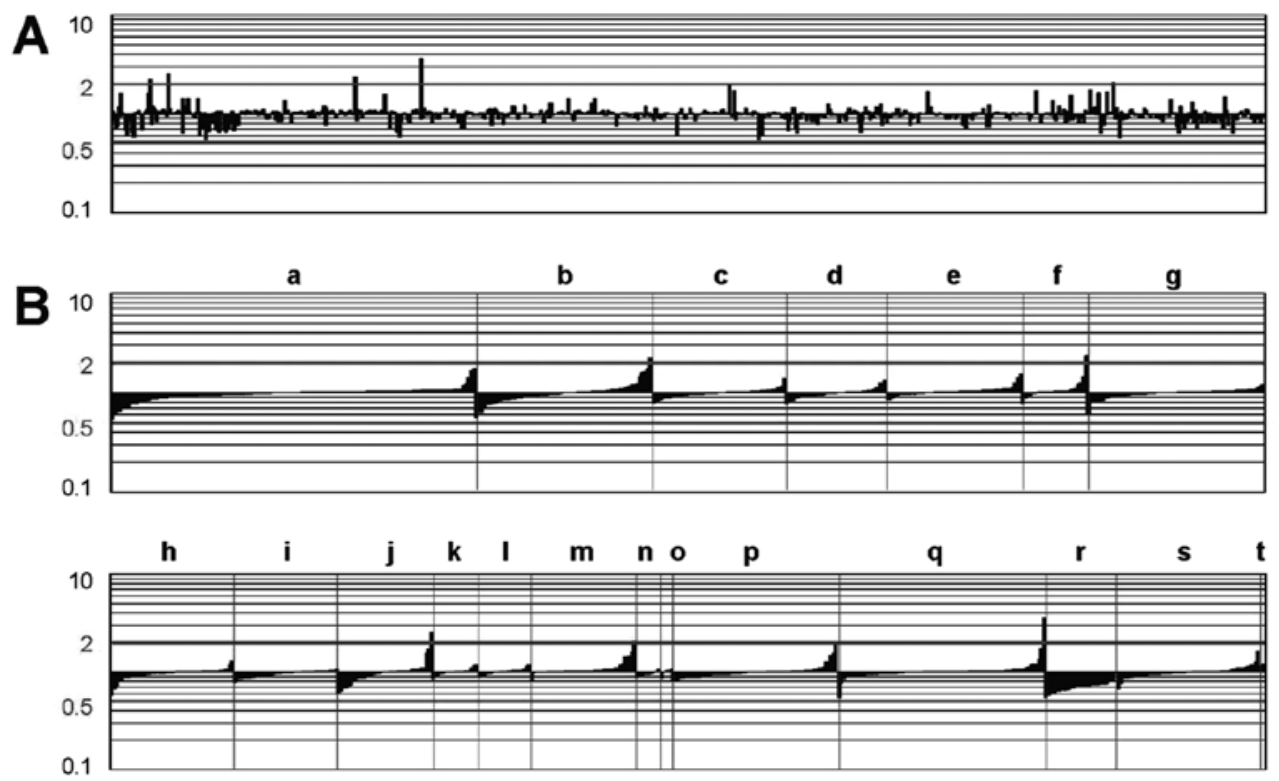

Figure 2. Gene expression profiles in UC patients, compared with normal subjects. The vertical bars indicate an increase or decrease in gene expression in patients with UC, compared with gene expression in control subjects, at a 2 -fold level of the Cy5/Cy3 ratio of the UC sample divided by the Cy5/Cy3 ratio of the normal sample. 'Downregulated' designates genes that are downregulated, compared with the control profile, at a 2-fold level; 'upregulated' indicates genes that are upregulated, compared with the control profile, at a 2-fold level. 'No significant change' indicates genes that are expressed within the 2-fold level. (A) Expression profiles of 776 genes based on the JGS ID number. (B) Expression profiles of genes based on their functional classifications. The 776 genes were divided into 20 groups based on their functional relatedness: lymphokine/cytokine/chemokine (a, $\mathrm{n}=134)$, cell surface antigen/immune (b, n=65), kinase/kinase inhibitor (c, n=49), apoptosis/stress $(\mathrm{d}, \mathrm{n}=37)$, matrix-related/membrane-bound $(\mathrm{e}, \mathrm{n}=50)$, metal (f, $\mathrm{n}=24)$, oncogene/suppressor $(\mathrm{g}$, $\mathrm{n}=65)$, cell cycle/transcription factor ( $\mathrm{h}, \mathrm{n}=49)$, DNA/RNA-binding protein $(\mathrm{i}, \mathrm{n}=42)$, energy/metabolism $(\mathrm{j}, \mathrm{n}=38)$, drug metabolism $(\mathrm{k}, \mathrm{n}=18)$, protease $(1$, $\mathrm{n}=21)$, serum protein/anti-coagulation $(\mathrm{m}, \mathrm{n}=42)$, proteasome $(\mathrm{n}, \mathrm{n}=10)$, autoimmune $(\mathrm{o}, \mathrm{n}=5)$, general enzyme $(\mathrm{p}, \mathrm{n}=66)$, receptor $(\mathrm{q}, \mathrm{n}=83)$, ribosomal protein $(\mathrm{r}, \mathrm{n}=29)$, miscellaneous $(\mathrm{s}, \mathrm{n}=57)$, and control $(\mathrm{t}, \mathrm{n}=2)$. Since a single gene occasionally belongs to more than one group, the total number of genes indicated on the $\mathrm{x}$-axis was 886 .

contrast, none of the genes were downregulated by $>2$-fold in the UC patients. Fig. 2B shows the expression profiles of the genes based on their functional classifications. Compared with normal subjects, gene expression in a variety of functional groups was altered in patients with UC.
Gene expression profiles: UC patients before LCAP vs. after $L C A P$. Fig. 3A shows the gene expression profiles of whole blood cells from UC patients before LCAP vs. those from the same patients after LCAP. The expression of several genes was altered following LCAP. Table IV displays several genes 
Table III. Genes upregulated >2-fold in whole blood cells of UC patients vs. normal subjects.

\begin{tabular}{|c|c|c|c|}
\hline Gene & GenBank no. & Group & Mean \\
\hline Galactoside-binding 3 (galectin 3); IgE-binding protein ( $\varepsilon-\mathrm{BP}$ ) & M57710 & $\mathrm{m}$ & 2.1 \\
\hline Immunoglobulin heavy constant $\gamma 3$ & J00230 & $\mathrm{b}$ & 2.2 \\
\hline Calcium binding protein in macrophages (MRP14) & X06233 & $\mathrm{f}$ & 2.3 \\
\hline$\gamma-\mathrm{G}$ globin $(\mathrm{HBG} 2)$ & X55656 & $\mathrm{j}$ & 2.5 \\
\hline Interleukin-1 receptor, type II (IL-1R2) & U74649 & $\mathrm{q}$ & 3.6 \\
\hline
\end{tabular}

Genes are related to cell surface antigens/immune response (b), metals (f), energy/metabolism (j), serum protein/anti-coagulation (m), or receptors (q). The groups correspond to those in Fig. 2B.
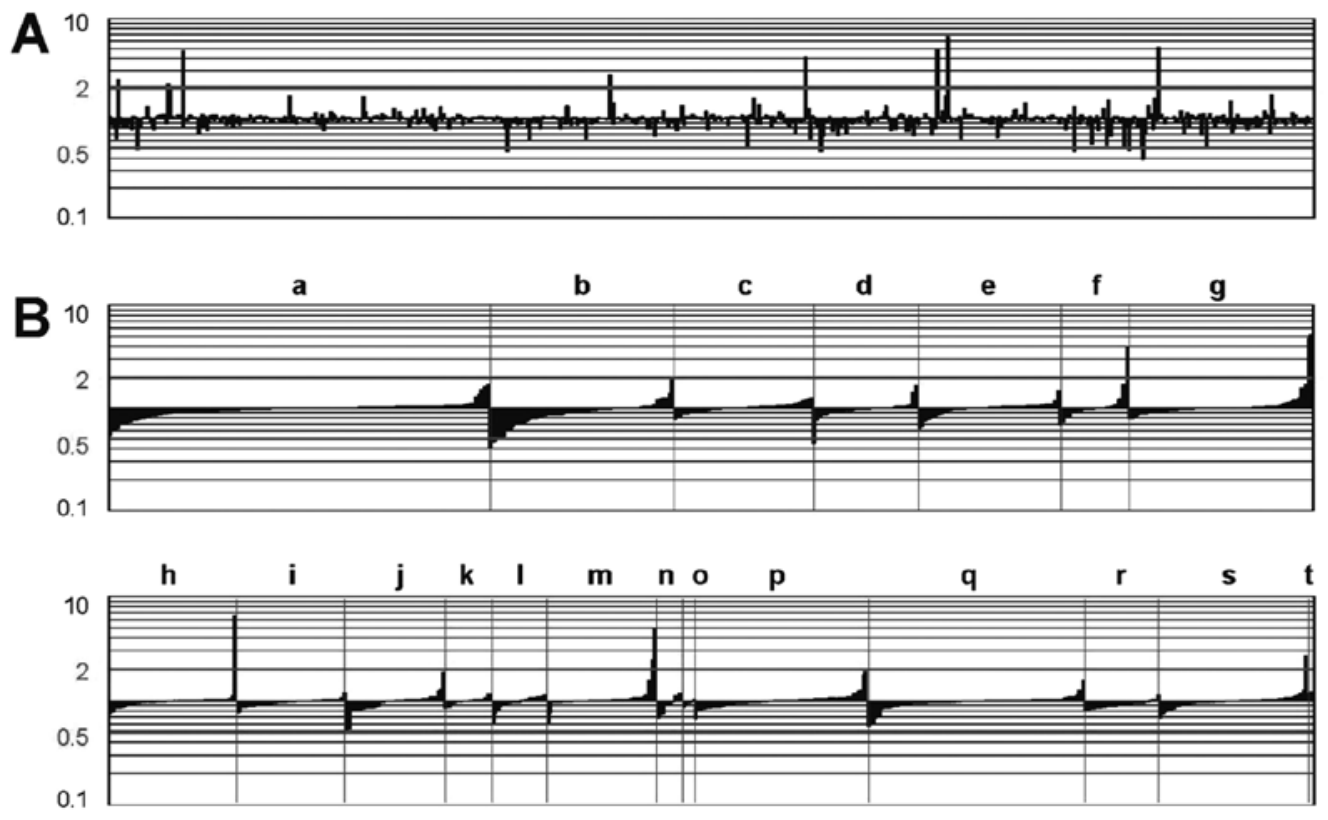

Figure 3. Gene expression profiles in UC patients after LCAP, compared with those before LCAP. The vertical bars indicate an increase or decrease in gene expression in UC patients after LCAP, compared with gene expression in UC patients before LCAP, at a 2-fold level of the Cy5/Cy3 ratio of the UC sample divided by the $\mathrm{Cy} 5 / \mathrm{Cy} 3$ ratio of the normal sample. 'Downregulated' designates genes that are downregulated, compared with the control profile, at a 2-fold level; 'upregulated' indicates genes that are upregulated, compared with the control profile, at a 2-fold level. 'No significant change' indicates genes that are expressed within the 2-fold level. (A) Expression profiles of 776 genes based on the JGS ID number. (B) Expression profiles of genes based on their functional classification. The 776 genes were divided into 20 groups based on their functional relatedness: lymphokine/cytokine/chemokine (a, $\mathrm{n}=134)$, cell surface antigen/immune (b, $\mathrm{n}=65)$, kinase/kinase inhibitor $(\mathrm{c}, \mathrm{n}=49)$, apoptosis/stress $(\mathrm{d}, \mathrm{n}=37)$, matrix-related/membrane-bound $(\mathrm{e}, \mathrm{n}=50)$, metal ( $\mathrm{f}, \mathrm{n}=24)$, oncogene/ suppressor ( $\mathrm{g}, \mathrm{n}=65)$, cell cycle/transcription factor ( $\mathrm{h}, \mathrm{n}=49$ ), DNA/RNA-binding protein $(\mathrm{i}, \mathrm{n}=42)$, energy/metabolism ( $\mathrm{j}, \mathrm{n}=38)$, drug metabolism $(\mathrm{k}, \mathrm{n}=18)$, protease $(1, n=21)$, serum protein/anti-coagulation $(m, n=42)$, proteasome $(n, n=10)$, autoimmune $(\mathrm{o}, \mathrm{n}=5)$, general enzyme $(\mathrm{p}, \mathrm{n}=66)$, receptor $(\mathrm{q}, \mathrm{n}=83)$, ribosomal protein $(r, n=29)$, miscellaneous $(s, n=57)$, and control $(t, n=2)$. Since a single gene occasionally belongs to more than one group, the total number of genes indicated on the $\mathrm{x}$-axis was 886 .

that were either upregulated or downregulated by $>2$-fold in UC patients who underwent LCAP. The downregulated transcripts included human leukocyte antigen (HLA)-DR $\beta 1$, HLA-DP light chain, CD74, CD97, and mangano-superoxide dismutase (Mn-SOD). In contrast, the upregulated transcripts included neutrophil gelatinase-associated lipocalin (NGAL), haptoglobin $\alpha 1 S, \alpha 1$-acid glycoprotein, fos, matrix metalloproteinase 8 (MMP8), and the putative lymphocyte G0/ G1 switch gene. Fig. 3B shows the expression profiles of the genes based on their functional classification. As a result of LCAP, widespread functional groups of genes were either upregulated or downregulated.

\section{Discussion}

The development of microarray techniques has recently provided new tools capable of providing a more comprehensive image of the gene expression profiles underlying disease states. Using this innovative approach, we hoped to identify the cellular expression patterns of UC patients treated with LCAP. Circulating blood is composed of heterogeneous and changing cell populations. The interactions of immune cell populations with non-immune cellular components of the blood and, occasionally, precursor cells are thought to be pivotal to the pathophysiology of UC. Therefore, we chose to 
Table IV. Genes upregulated or downregulated >2-fold in whole blood cells of pre-LCAP vs. post-LCAP UC patients.

\begin{tabular}{|c|c|c|c|c|}
\hline Gene & GenBank no. & Group & Mean & SD \\
\hline \multicolumn{5}{|l|}{ Downregulated genes } \\
\hline Human leukocyte antigen (HLA)-DR $\beta 1$ & M20430 & $\mathrm{b}$ & 0.4 & 0.1 \\
\hline Mangano-superoxide dismutase (Mn-SOD) & X14322 & $\mathrm{d}$ & 0.5 & 0.1 \\
\hline HLA-DP light chain & M57466 & $\mathrm{b}$ & 0.5 & 0.1 \\
\hline CD74 & ВC018726 & $\mathrm{b}$ & 0.5 & 0.1 \\
\hline CD97 & U76764 & $\mathrm{b}$ & 0.5 & 0.1 \\
\hline \multicolumn{5}{|l|}{ Upregulated genes } \\
\hline$\alpha-1$ acid glycoprotein (orosomucoid-1) & M13692 & $\mathrm{m}$ & 2.5 & 1.0 \\
\hline Matrix metalloproteinase 8 (neutrophil collagenase) & J05556 & $\mathrm{f}$ & 3.9 & 2.7 \\
\hline Fos & ВC004490 & $\mathrm{g}$ & 4.7 & 3.3 \\
\hline Haptoglobin $\alpha 1 \mathrm{~S}$ & X00637 & $\mathrm{m}$ & 5.0 & 3.4 \\
\hline Neutrophil gelatinase-associated lipocalin (NGAL) & X83006 & $\mathrm{g}$ & 5.2 & 3.3 \\
\hline Putative lymphocyte G0/G1 switch gene & M72885 & $\mathrm{h}$ & 6.5 & 4.5 \\
\hline
\end{tabular}

Genes are related to cell surface antigens/immune response (b), apoptosis/stress (d), metals (f), oncogenes/suppressors (g), cell cycle/transcription factors $(\mathrm{h})$, serum protein/anti-coagulation $(\mathrm{m})$, or miscellaneous factors $(\mathrm{s})$. The groups correspond to those in Fig. 3B.

use RNA from whole blood cells, which comprises heterogeneous cell types, with the specific purpose of gaining a global and representative insight into all cellular changes associated with LCAP. Furthermore, we used freshly obtained peripheral blood samples, and the RNA was immediately stabilized in Pax-Gene tubes. This protocol is critical because it has been previously shown that even short-term ex vivo incubations of blood cells can alter expression profiles (27).

We first compared the gene expression profiles of whole blood cells from UC patients with those from normal subjects. Our results identified several upregulated genes including IL-1R2, an IL-1R that antagonizes IL-1-mediated events (28), and MRP-14, a calcium-binding protein expressed during chronic inflammation (29). Several genes that have not been previously linked to UC, such as HBG2 (30), galectin 3 (31), and immunoglobulin heavy constant $\gamma 3$ (32), were also upregulated. The widespread upregulation of these genes involved in receptor (IL-1R2), metal (MRP-14), energy/metabolism (HBG2), serum protein/anti-coagulation (galectin 3), and cell surface antigen/immune (immunoglobulin heavy constant $\gamma 3$ ) processes may indicate a major disruption in cellular homeostasis in UC. Further studies are needed to elucidate whether the gene expression profile observed in this study is specific to UC or merely a secondary event associated with intestinal inflammation.

LCAP is a therapeutic strategy involving extracorporeal immunomodulation that has been used to treat several immunological disorders including UC (8-11) and Crohn's disease (12). A multicenter, randomized controlled trial of UC patients showed that the efficacy of LCAP was significantly superior to that of high-dose steroid therapy (9). Recent research has revealed that LCAP preferentially attenuates inflammatory and immune responses through the downregulation of proinflammatory mediators, such as IL-1, tumor necrosis factor- $\alpha$ or adhesion molecules, or the upregulation of anti-inflammatory mediators, such as IL-4 or IL-10 (33-35). In the present study, we focused on, for the first time, the effect of LCAP on the gene expression profiles of whole blood cells from UC patients.

LCAP downregulated the expression of proinflammatory genes that belong to the cell surface antigen/immune response group, including CD97, CD74, HLA-DR 31 and HLA-DP light chain. CD97 has an essential role in the migration of neutrophils by facilitating the binding of chemokines (36). In fact, the homing of adoptively transferred neutrophils to the colon was delayed when the cells were preincubated with anti-CD97 monoclonal antibodies in experimental colitis (37). CD74, a cell surface binding protein for macrophage migration inhibitory factor (MIF), is required for the MIF-induced activation of the extracellular signal-regulated kinase-1/2 kinase cascade, cell proliferation, and prostaglandin E2 production (38). Moreover, MIF, the ligand for CD74, plays a key role in the development of IBD (39). The downregulation of HLA-related genes, such as HLA-DR $\beta 1$ and HLA-DP light chain, may imply an improvement in the abnormal immune regulation observed in UC (40).

Notably, LCAP upregulated the expression of natural antimicrobial NGAL, a neutrophil lipocalin that may bind the proinflammatory bacterial tripeptide N-formylmethionylleucyl-phenylalanine (41). In situ hybridization and immunohistochemical studies have shown strong NGAL expression in colonocytes and neutrophils in patients with UC (42). Since enteric flora plays an important role in the pathogenesis of UC, the upregulation of such genes lends particularly strong support to the effectiveness of LCAP. Moreover, several acute phase protein genes, including haptoglobin $\alpha 1 \mathrm{~S}$ and $\alpha 1$-acid glycoprotein, were upregulated after LCAP. Previous studies have shown that haptoglobin, found in chronic inflammatory conditions, can aid in tissue repair by stimulating angiogenesis (43). Furthermore, $\alpha 1$-acid glycoprotein can prevent neutrophil activation during inflammatory processes (44). Therefore, the LCAP-induced upregulation of these three genes seems to play a protective role in patients 
with UC. The functional roles of the upregulation of Mn-SOD (45), the putative lymphocyte G0/G1 switch gene (46), fos (47) and MMP8 (48) remain unclear.

How does LCAP alter these cellular gene expression profiles? During LCAP, most of the leukocytes are removed by a filter during extracorporeal circulation. This treatment is associated with rebound leukophilia in response to transient leukopenia $(49,50)$, indicating a rapid cell release response from the reticuloendothelial system. Therefore, this drastic change in gene expression may be partly explained by the replacement of activated leukocytes with new and naïve ones originating from the marginated pool and/or bone marrow. We cannot completely exclude the possibility that some of the identified differences in gene expression before and after LCAP may be the result of a distinct composition of leukocyte subsets, since the proportion of neutrophils increased and the proportion of lymphocytes and monocytes decreased after LCAP.

Medical therapies for IBD are predominantly directed at attenuating inflammatory and immune processes using glucocorticoids, immunosuppressants, and/or cytokine inhibitors $(51,52)$. New therapeutic approaches that may change the enteric flora, promote tissue repair, or enhance the antiinflammatory aspects of the disease have also been employed $(53,54)$. Since the analyses in the present study were conducted using only six samples obtained from patients after their first session of LCAP, we could not clarify whether the change in the cellular gene expression profiles directly contributed to the positive clinical outcomes after a full course of LCAP. However, taking into consideration the evidence presented here, we speculate that LCAP preferentially downregulates genes related to disease progression and upregulates those related to disease amelioration.

In conclusion, we identified, for the first time, the gene expression profile of whole blood cells from patients with UC and the transcriptional events following LCAP. After LCAP, the gene expression profile shifted toward one indicating disease improvement. These results suggest a basis for the molecular mechanisms leading to the therapeutic effects of LCAP as well as indicating new therapeutic targets, thereby providing important prognostic information.

\section{Acknowledgements}

This study was supported in part by Grants-in-Aid from the Japanese Ministry of Education, Culture, and Science; and the Japanese Ministry of Health and Welfare. We thank Ms. Ritsuko Seki and Ms. Asako Hitomi, Mr. Tomoshige Nogami and Mr. Hiroshi Shibata for their help during the study.

\section{References}

1. Podolsky DK: Inflammatory bowel disease. N Engl J Med 347: 417-429, 2002.

2. Bamias G, Nyce MR, De La Rue SA, Cominelli F; American College of Physicians; American Physiological Society: New concepts in the pathophysiology of inflammatory bowel disease. Ann Intern Med 143: 895-904, 2005.

3. Targan SR and Karp LC: Defects in mucosal immunity leading to ulcerative colitis. Immunol Rev 206: 296-305, 2005.

4. Grimm MC, Pullman WE, Bennett GM, Sullivan PJ, Pavli P and Doe WF: Direct evidence of monocyte recruitment to inflammatory bowel disease mucosa. J Gastroenterol Hepatol 10: 387-395, 1995.
5. Rugtveit J, Brandtzaeg P, Halstensen TS, Fausa $\mathrm{O}$ and Scott $\mathrm{H}$ : Increased macrophage subset in inflammatory bowel disease: apparent recruitment from peripheral blood monocytes. Gut 35: 669-674, 1994.

6. Kondoh T, Hidaka Y, Katoh H, Inoue N and Saito S: Evaluation of a filtration lymphocytapheresis (LCP) device for use in the treatment of patients with rheumatoid arthritis. Artif Organs 15: 180-188, 1991.

7. Sawada K, Ohnishi K, Fukui S, et al: Leukocytapheresis therapy, performed with leukocyte removal filter, for inflammatory bowel disease. J Gastroenterol 30: 322-329, 1995.

8. Ortolano GA, Capetandes A and Wenz B: A review of leukofiltration therapy for decreasing the morbidity associated with cardiopulmonary bypass and acute inflammatory bowel disease. Ther Apher 6: 119-129, 2002.

9. Sawada K, Muto T, Shimoyama T, et al: Multicenter randomized controlled trial for the treatment of ulcerative colitis with a leukocytapheresis column. Curr Pharm Des 9: 307-321, 2003.

10. Yajima T, Takaishi H, Kanai T, et al: Predictive factors of response to leukocytapheresis therapy for ulcerative colitis. Ther Apher 2: 115-119, 1998.

11. Sasaki M, Tsujikawa T, Fujiyama Y and Bamba T: Leukocytapheresis therapy for severe ulcerative colitis. Ther Apher 2: 101-104, 1998.

12. Kosaka T, Sawada K, Ohnishi K, et al: Effect of leukocytapheresis therapy using a leukocyte removal filter in Crohn's disease. Intern Med 38: 102-111, 1999.

13. Hidaka T, Suzuki K, Matsuki Y, et al: Filtration leukocytapheresis therapy in rheumatoid arthritis: a randomized, double-blind, placebo-controlled trial. Arthritis Rheum 42: 431-437, 1999.

14. Ueki Y, Yamasaki S, Kanamoto Y, et al: Evaluation of filtration leucocytapheresis for use in the treatment of patients with rheumatoid arthritis. Rheumatology 39: 165-171, 2000.

15. Furuta T, Hotta O, Yusa N, Horigome I, Chiba S and Taguma Y: Lymphocytapheresis to treat rapidly progressive glomerulonephritis: a randomised comparison with steroid-pulse treatment. Lancet 352: 203-204, 1998.

16. Dieckgraefe BK, Stenson WF, Korzenik JR, Swanson PE and Harrington CA: Analysis of mucosal gene expression in inflammatory bowel disease by parallel oligonucleotide arrays. Physiol Genomics 4: 1-11, 2000

17. Lawrance IC, Fiocchi $C$ and Chakravarti S: Ulcerative colitis and Crohn's disease: distinctive gene expression profiles and novel susceptibility candidate genes. Hum Mol Genet 10: 445-456, 2001.

18. Heller RA, Schena M, Chai A, et al: Discovery and analysis of inflammatory disease-related genes using cDNA microarrays. Proc Natl Acad Sci USA 94: 2150-2155, 1997.

19. Truelove SC and Witts LJ: Cortisone in ulcerative colitis; final report on a therapeutic trial. Br Med J 2: 1041-1048, 1955.

20. Nagase K, Sawada K, Ohnishi K, Egashira A, Ohkusu K and Shimoyama T: Complications of leukocytapheresis. Ther Apher 2: $120-124,1998$.

21. Hashimoto S, Suzuki T, Dong HY, Yamazaki N and Matsushima K: Serial analysis of gene expression in human monocytes and macrophages. Blood 94: 837-844, 1999.

22. Hashimoto S, Suzuki T, Dong HY, Nagai S, Yamazaki N and Matsushima K: Serial analysis of gene expression in human monocyte-derived dendritic cells. Blood 94: 845-852, 1999.

23. Hashimoto SI, Suzuki T, Nagai S, Yamashita T, Toyoda N and Matsushima K: Identification of genes specifically expressed in human activated and mature dendritic cells through serial analysis of gene expression. Blood 96: 2206-2214, 2000.

24. Nagai S, Hashimoto S, Yamashita T, et al: Comprehensive gene expression profile of human activated T(h)1- and T(h)2-polarized cells. Int Immunol 13: 367-376, 2001.

25. Khodursky AB, Peter BJ, Cozzarelli NR, Botstein D, Brown PO and Yanofsky C: DNA microarray analysis of gene expression in response to physiological and genetic changes that affect tryptophan metabolism in Escherichia coli. Proc Natl Acad Sci USA 97: 12170-12175, 2000.

26. Yang YH, Dudoit S, Luu P, et al: Normalization for cDNA microarray data: a robust composite method addressing single and multiple slide systematic variation. Nucleic Acids Res 30: $\mathrm{e} 15,2002$.

27. Baechler EC, Batliwalla FM, Karypis G, et al: Expression levels for many genes in human peripheral blood cells are highly sensitive to ex vivo incubation. Genes Immun 5: 347-353, 2004.

28. Rauschmayr T, Groves RW and Kupper TS: Keratinocyte expression of the type 2 interleukin 1 receptor mediates local and specific inhibition of interleukin 1-mediated inflammation. Proc Natl Acad Sci USA 94: 5814-5819, 1997. 
29. Odink K, Cerletti N, Bruggen J, et al: Two calcium-binding proteins in infiltrate macrophages of rheumatoid arthritis. Nature 330: 80-82, 1987.

30. Cui XF, Li HH, Goradia TM, et al: Single-sperm typing: determination of genetic distance between the $\mathrm{G}$ gamma-globin and parathyroid hormone loci by using the polymerase chain reaction and allele-specific oligomers. Proc Natl Acad Sci USA 86: 9389-9393, 1989.

31. Robertson MW, Albrandt K, Keller D and Liu FT: Human IgE-binding protein: a soluble lectin exhibiting a highly conserved interspecies sequence and differential recognition of IgE glycoforms. Biochemistry 29: 8093-8100, 1990.

32. Takahashi N, Ueda S, Obata M, Nikaido T, Nakai S and Honjo T: Structure of human immunoglobulin gamma genes: implications for evolution of a gene family. Cell 29: 671-679, 1982.

33. Mitsuyama K, Suzuki A, Matsumoto S, et al: Diminished cytokine signalling against bacterial components in mononuclear leucocytes from ulcerative colitis patients after leukocytapheresis. Clin Exp Immunol 141: 130-140, 2005.

34. Andoh A, Ogawa A, Kitamura K, et al: Suppression of interleukin-1beta- and tumor necrosis factor-alpha-induced inflammatory responses by leukocytapheresis therapy in patients with ulcerative colitis. J Gastroenterol 39: 1150-1157, 2004.

35. Noguchi M, Hiwatashi N, Hayakawa T and Toyota T: Leukocyte removal filter-passed lymphocytes produce large amounts of interleukin-4 in immunotherapy for inflammatory bowel disease: role of bystander suppression. Ther Apher 2: 109-114, 1998.

36. Gray JX, Haino M, Roth MJ, et al: CD97 is a processed, seven-transmembrane, heterodimeric receptor associated with inflammation. J Immunol 157: 5438-5447, 1996.

37. Leemans JC, te Velde AA, Florquin S, et al: The epidermal growth factor-seven transmembrane (EGF-TM7) receptor CD97 is required for neutrophil migration and host defense. J Immunol 172: 1125-1131, 2004.

38. Leng L, Metz CN, Fang Y, et al: MIF signal transduction initiated by binding to CD74. J Exp Med 197: 1467-1476, 2003.

39. Ohkawara T, Nishihira J, Takeda $\mathrm{H}$, et al: Amelioration of dextran sulfate sodium-induced colitis by anti-macrophage migration inhibitory factor antibody in mice. Gastroenterology 123: 256-270, 2002.

40. Salomon P, Pizzimenti A, Panja A, Reisman A and Mayer L: The expression and regulation of class II antigens in normal and inflammatory bowel disease peripheral blood monocytes and intestinal epithelium. Autoimmunity 9: 141-149, 1991.

41. Kjeldsen L, Johnsen AH, Sengelov $\mathrm{H}$ and Borregaard N: Isolation and primary structure of NGAL, a novel protein associated with human neutrophil gelatinase. J Biol Chem 268: 10425-10432, 1993.
42. Nielsen BS, Borregaard N, Bundgaard JR, Timshel S, Sehested M and Kjeldsen L: Induction of NGAL synthesis in epithelial cells of human colorectal neoplasia and inflammatory bowel diseases. Gut 38: 414-420, 1996

43. Cid MC, Grant DS, Hoffman GS, Auerbach R, Fauci AS and Kleinman HK: Identification of haptoglobin as an angiogenic factor in sera from patients with systemic vasculitis. J Clin Invest 91: 977-985, 1993.

44. Laine E, Couderc R, Roch-Arveiller M, Vasson MP, Giroud JP and Raichvarg D: Modulation of human polymorphonuclear neutrophil functions by alpha 1-acid glycoprotein. Inflammation 14: 1-9, 1990.

45. Wispe JR, Clark JC, Burhans MS, Kropp KE, Korfhagen TR and Whitsett JA: Synthesis and processing of the precursor for human mangano-superoxide dismutase. Biochim Biophys Acta 994: 30-36, 1989.

46. Russell L and Forsdyke DR: A human putative lymphocyte G0/ G1 switch gene containing a CpG-rich island encodes a small basic protein with the potential to be phosphorylated. DNA Cell Biol 10: 581-591, 1991.

47. Warburton G, Nares S, Angelov N, Brahim JS, Dionne RA and Wahl SM: Transcriptional events in a clinical model of oral mucosal tissue injury and repair. Wound Repair Regen 13: 19-26, 2005.

48. Pirila E, Ramamurthy NS, Sorsa T, Salo T, Hietanen J and Maisi P: Gelatinase A (MMP-2), collagenase-2 (MMP-8), and laminin-5 gamma2-chain expression in murine inflammatory bowel disease (ulcerative colitis). Dig Dis Sci 48: 93-98, 2003.

49. Yamaji K, Yang K, Tsuda $\mathrm{H}$ and Hashimoto H: Fluctuations in the peripheral blood leukocyte and platelet counts in leukocytapheresis in healthy volunteers. Ther Apher 6: 402-412, 2002.

50. Sawada K, Ohnishi K, Kosaka T, et al: Leukocytapheresis with leukocyte removal filter as new therapy for ulcerative colitis. Ther Apher 1: 207-211, 1997.

51. Danese S: New therapies for inflammatory bowel disease: from the bench to the bedside. Gut 61: 918-932, 2012.

52. Rutgeerts P, Vermeire S and Van Assche G: Biological therapies for inflammatory bowel diseases. Gastroenterology 136: 1182-1197, 2009.

53. Mitsuyama K and Sata M: Gut microflora: a new target for therapeutic approaches in inflammatory bowel disease. Expert Opin Ther Targets 12: 301-312, 2008.

54. Duijvestein M, van den Brink GR and Hommes DW: Stem cells as potential novel therapeutic strategy for inflammatory bowel disease. J Crohns Colitis 2: 99-106, 2008. 